\title{
New considerations for colorectal cancer screening based on the demographic profile of colorectal cancer in a Greek population
}

\author{
VASILEIOS PANTERIS ${ }^{1}$, PANAGIOTIS KARANTANOS ${ }^{1}$, NIKOLAOS VASILAKIS ${ }^{1}$, STEPHANIE VGENOPOULOU ${ }^{2}$, \\ GEORGIA LYMPEROPOULOU $^{1}$, GEORGIOS FERETZAKIS ${ }^{3}$, ILIAS DALAINAS ${ }^{4}$ and ELIAS KOUROUMALIS ${ }^{5}$ \\ ${ }^{1}$ Gastroenterology Department, ${ }^{2}$ Histopathology Department, ${ }^{3}$ Department of Quality Control, Research and \\ Continuing Education and ${ }^{4}$ General Manager, Sismanogleio-Amalia Fleming General Hospital, 15126 Athens; \\ ${ }^{5}$ University of Crete Medical School, 71500 Heraklion, Greece
}

Received August 30, 2021; Accepted November 12, 2021

DOI: $10.3892 / \mathrm{mco} .2022 .2490$

\begin{abstract}
Colorectal cancer screening has long been recommended for middle age and older individuals. Recent evidence indicates increasing incidence and mortality among young adults. Therefore, the present study re-examined the current recommendations using an asymptomatic average-risk population screened by colonoscopy. A total of 716 participants of a wide age range were prospectively enrolled in an open-access endoscopic screening program based on self-referral. Comparisons between different age, gender and location groups, and receiver operating characteristic curves (ROC) curves for best age selection for detection of lesions were employed. Increased incidence of advanced lesions was observed in adults $<50$ years old. Although the polyp size was $<1 \mathrm{~cm}$ in $85 \%$ of the cohort, a significant number of participants harbored advanced lesions. A disturbing incidence of lesions in women 30-49 years was located mainly in the left colon. One-third of the important pathology resides exclusively in the right colon. ROC curves demonstrated that with the current starting age of screening at 50 years, $92 \%$ of polyps and $95 \%$ of adenomas could be detected by colonoscopy, but a number of potential precancerous lesions will appear at an earlier age and therefore will be missed. The present study supported the notion that it is critical to reduce screening initiation below the currently accepted age of 50 years. Colonoscopy is a suitable method for addressing the increased prevalence of proximal lesions and the meticulous resection of smaller polyps.
\end{abstract}

Correspondence to: Dr Vasileios Panteris, Gastroenterology Department, Sismanogleio-Amalia Fleming General Hospital, Sismanogliou 37, Marousi, 15126 Athens, Greece

E-mail: vasileios.panteris@gmail.com

Key words: colorectal cancer, screening, Greek cohort, colonoscopy, public health

\section{Introduction}

It is generally accepted that the management of colorectal cancer (CRC) has been successfully improved. This is indicated by the confirmation of declining incidence and mortality since 1975 and documented in successive annual reports on CRC, spanning over the last decade in the western world. This success has been mainly attributed to identifying modifiable lifestyle risk factors and the wider application of screening and subsequently endoscopic polypectomy (1-3).

Unfortunately, recent evidence tarnished the current euphoria. Increasing incidence and mortality in young adults $<50$ years old have been reported $(3,4)$. An inconspicuous increase in CRC incidence in younger individuals appeared in the early 1990s $(4,5)$, but it was more widely recognized during the last decade $(5,6)$. This recognition identified CRC as the second most common cancer after the age of 30 years (7) and as the fourth leading cause of mortality in adolescents and young adults (3).

Women seem to be more susceptible to an increased CRC annual percent change (APC) in younger cohorts (30-49 years old), which is higher compared with men and consistent across continents of the western culture (USA, Australia, Europe) $(6,8,9)$. Furthermore, an inverse correlation exists in women where the overall decreasing incidence of CRC is faster in men while the decreasing overall mortality is slower in women (3).

High rates of proximal colon cancers have been estimated to be between $30-42 \%$ of the total prevalence, being more common in men compared with women $(10,11)$. Increasing incidences of proximal cancers in young adults 20-49 years old have also been reported, especially after $2010(5,12)$

The vast majority (80\%) of polyps found during average-risk screening colonoscopy are subcentimetric polyps $(<10 \mathrm{~mm})(13,14)$. At the same time, they constitute a potential cause of pitfalls for the endoscopist since they may harbor significant lesions, such as advanced adenomas $(\leq 12.8 \%)(15)$, while the methods for their resection are imperfect $(16,17)$.

Screening has been considered to contribute to the decline in CRC incidence and mortality. By contrast, the lack of adequate screening may have threatening repercussions in younger individuals regarding the $\mathrm{CRC}$ risk $(4,18)$. To achieve 
this goal, worldwide guidelines recommend the initiation of screening at 50 years old since two-thirds of CRC cases are detected in individuals $\geq 60$ years old and $90 \%$ in those $>50$ years old $(8,19)$. Recent recommendations suggest that screening should start earlier at 45 years old (18).

The present study therefore aimed to address the issues aforementioned by analyzing epidemiological data from an average risk asymptomatic screening cohort of a wide age range that was submitted to colonoscopy in an open-access manner in the endoscopy unit of a tertiary hospital. Since there is no national organized screening program in Greece, the current study will provide the opportunity to collect and interpret real-life data from a population sample in a densely populated urban area of westernized lifestyle to demonstrate actual needs for health policymaking.

\section{Materials and methods}

The present study prospectively included 716 individuals submitted to screening colonoscopy during a period of 2 years (2017-2018). They have been classified as average risk since those with a personal or family history of polyps and colorectal cancer and those with prior positive fecal hemoglobin tests, blood per rectum or inflammatory bowel disease and anemia were excluded. They were all asymptomatic except for the occasional sporadic abdominal discomfort, which was considered non-significant. Their examination was performed on an open-access endoscopy screening program after self-referral and personal informed consent. The procedure was completed under conscious sedation after bowel cleansing using a polyethylene glycol preparation. The bowel cleansing was graded on a three-class scale (good, adequate, poor) similar to the Boston Preparation Scale. In case polyps were discovered during colonoscopy, they were excised by cold biopsy forceps or by cold or hot snaring at the endoscopist's discretion. The size of the polyps was estimated compared with open biopsy forceps with an opening diameter of $7 \mathrm{~mm}$. The extend of the right colon was considered up to the splenic flexure and that of the left colon from the splenic flexure and peripherally up to the anal verge. Information was collected from the endoscopic and pathologic reports. During endoscopic sessions, both consultants and trainees were involved. Per patient analysis was performed according to the maximum polyp size when more than one polyp of different sizes was found. Advanced adenomas (AA) were defined as polyps with size $\geq 10 \mathrm{~mm}$ or with high-grade dysplasia (hgd). Since there was a substantial inter-observer variation for recognizing a villous component, this parameter was not included in the definition of AA (20). The protocol of the present study was accepted by the Sismanogleio-Amalia Fleming Hospital's scientific review committee (approval number 399/18-4-2019) and conformed to the amendments of the Helsinki Declaration.

Statistical analysis. Continuous variables were compared between groups using the t-test and for more than two levels of explanatory variables using one-way ANOVA. Ordinal data were compared using the $\chi^{2}$ and post hoc comparisons were performed by the Bonferroni method. Receiver operating characteristic curves (ROC) were produced to define the appropriate age providing optimum sensitivity for adenoma detection. The number needed to screen (NNS) to detect one adenoma was estimated across different age and gender groups. The a-level was defined as significant at 0.05. All P-values were 2-sided. The statistical package used for analytical statistics was the SPSS 27 (IBM Corp.).

\section{Results}

General overview. There were 716 participants with a median age of 63 years (range $30-87$ years), and $51.3 \%$ were males. The cecum was reached in $95.7 \%$ of the cases. The preparation was considered as good or adequate in $92 \%$ of the endoscopies. A consultant performed the colonoscopy in $69 \%$ of the sessions and the rest by a trainee under supervision with an overall adenoma detection rate of $28.4 \%$. The prevalence of lesions including polyps, adenomas, advanced adenomas, high-grade dysplasia, and cancer are shown in Table I. Polyps were found in $52.4 \%(n=375)$ of the entire cohort. The median number of polyps/person was 2. Marked proportions of the lesions above were found in this average risk screening cohort. This has important implications concerning the epidemiologic burden and the risk of future cancer development in the population.

Associations of polyp size and location with important lesions. Most subjects with polyps $(58.1 \%)$ had a maximum polyp size of $6-9 \mathrm{~mm}$. Only $14.7 \%$ of them had polyps $\geq 10 \mathrm{~mm}$. There is a linear association between increasing polyp size and age as well as the prevalence of adenomas, hgd, cancer, serrated pathology, and the location at the right colon. Nonetheless, a significant proportion of the diminutive and small polyps harbor important lesions (48\% adenomas, 5.6\% hgd, $12.9 \%$ serrated, and $0.9 \%$ coexist with cancer lesions) while $15 \%$ of the screened participants present with isolated right colon lesions of this size (Table II).

AA appeared in $9.6 \%$ of the attendees, mostly in men $(67 \%$ of AA), in the intermediate age group (50-69 years old; $56.2 \%$ of AA), with a significant proportion of them located at the right colon $(39 \%)$ and $25 \%$ of those were found in $6-9 \mathrm{~mm}$ polyps. The mean size of AA was $15 \mathrm{~mm}$, and the median number per patient was 1 . In Table III, the distribution of characteristics between the isolated right and left colon lesions was shown. Isolated right colon lesions were found in older individuals with increasing frequency, with no significant gender difference but with a male predominance, harboring important pathology ( one-third of serious lesions reside in that part of the bowel). As maximum polyp size increases $>9 \mathrm{~mm}$, almost half $(43.3 \%)$ of the participants accommodate lesions in the right colon.

The epidemiologic profile according to different age groups. A comparison between age groups is presented in Table IV. It seems that between the early (30-49 years old) and intermediate (50-69 years old) age groups, there is no quantitative or qualitative difference in important pathologies (mean number and size of lesions, proportion of AA, hgd, cancer and isolated right colon lesions). Apart from the prevalence of polyps and adenomas that follow a linear association with increasing age and the disparities in the presence of SSP/A (sessile serrated polyp/adenoma) that in any case represent an alternative cancer pathway, it seems that younger individuals (30-49 years old) 
Table I. Characteristics of participants.

\begin{tabular}{lc}
\hline Total no. & 716 \\
\hline Age, median, (range) & $63(30-87)$ \\
Sex, n (\%) & \\
Male & $367(51.3)$ \\
Female & $349(48.7)$ \\
Prevalence of lesions, n (\%) & \\
Any polyp & $375(52.4)$ \\
Adenoma & $205(28.6)$ \\
Advanced Adenoma & $69(9.6)$ \\
High grade dysplasia & $31(4.3)$ \\
Cancer & $10(1.4)$ \\
SSP/A & $54(7.5)$ \\
Location & $156(21.7)$ \\
Right colon lesions, $\mathrm{n}(\%)$ & 2 \\
No polyps/pt, median & 1 \\
No adenoma/pt, median &
\end{tabular}

Any polyp: all screens with polyp of any type. SSP/A, sessile serrated polyp/adenoma.

have acquired a risk profile that needs to be taken into account by future screening policy recommendations.

Gender influences across different age groups. In Table V, the findings showed that women 30-49 years old have a higher prevalence of polyps of larger size and cancer cases compared with men, although this was not statistically significant. There was no significant difference in frequency characteristics between women of 30-49 years old and women of 50-69 years old (data not shown) except for the prevalence of SSP/A. Females of a younger age had their polyps, AA and hgd located in the left colon (absence of isolated right colon lesions). By contrast, men show a marked increase in the prevalence and size of polyps and prevalence of adenomas and AA at the next age group of 50-69 years old, with frequencies higher compared with the respective age group of females. Men 30-49 years old show polyps distributed throughout the left and right colon and important lesions, such as AA and hgd in the right colon (absence of isolated left colon lesions). There was a linear association for right colon lesions with increasing age in women. Nonetheless, males maintain the majority of proximal lesions in all age groups. These findings indicate a trend towards an additional disease burden in young women, which is located in the easily accessible left colon.

Implications based on ROC curves analysis. ROC curves (Table VI) were generated to predict the detection of adenomas at each age group by colonoscopic screening. In every screening program, one of the most important determinants is the sensitivity of the detection method. The area under the curve predicted that at 50 years old, a colonoscopy will detect $92 \%$ of the polyps (Fig. 1), $95 \%$ of the adenomas (Fig. 2), and 93\% of the AA (Fig. 3) and proximal lesions (Fig. 4). When ROC curves were applied for males and females separately

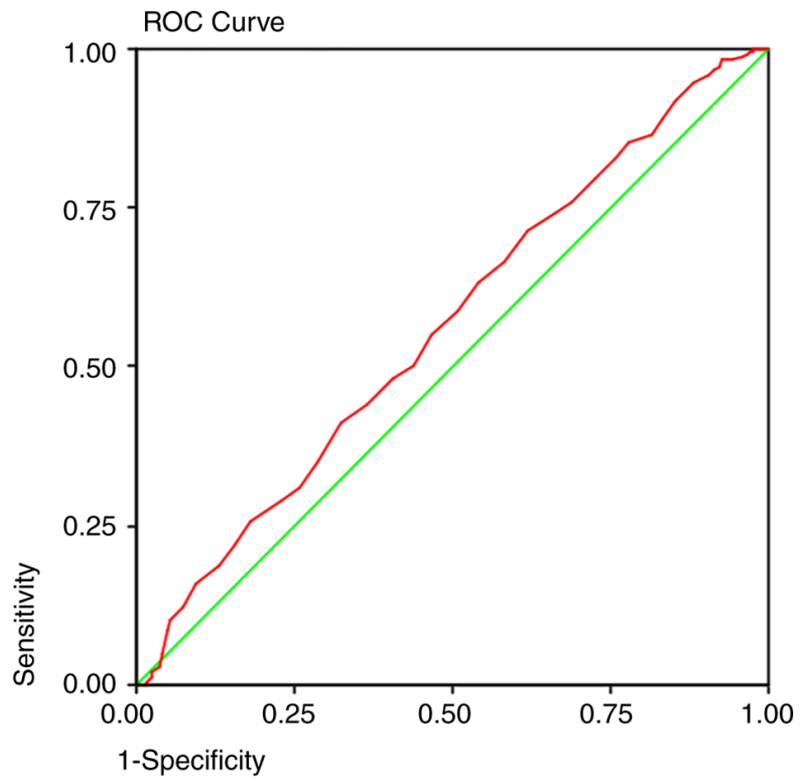

Figure 1. ROC curve for polyp detection. ROC, receiver operating characteristic.

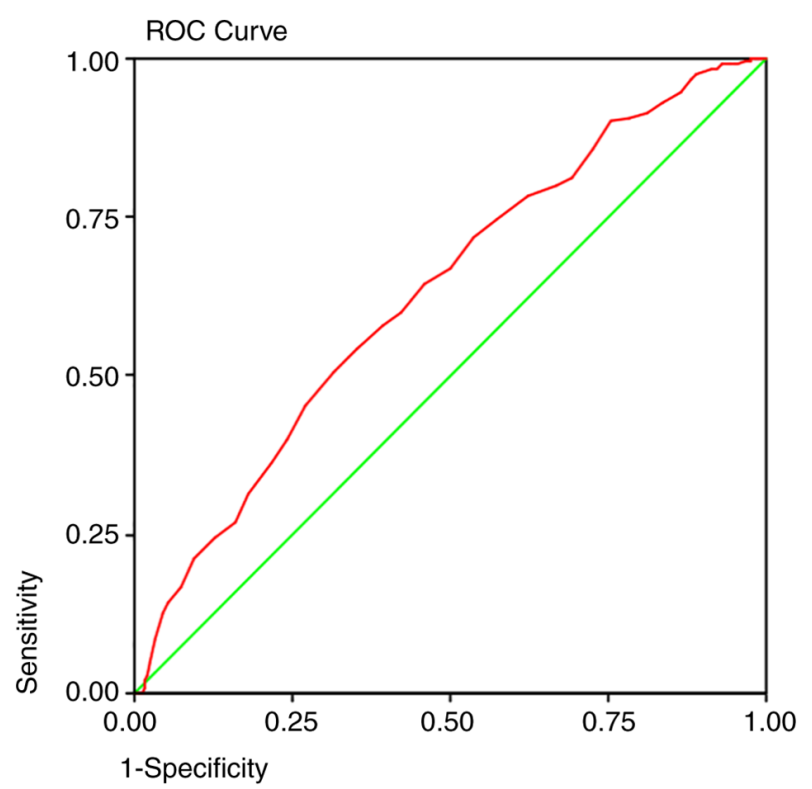

Figure 2. ROC curve for adenoma detection. ROC, receiver operating characteristic.

(Figs. 5 and 6 respectively), the area under the curve for the detection of adenomas demonstrated 95 and $93 \%$ sensitivity, respectively, at the same age limit (50 years old).

\section{Discussion}

Since 2003, when the European Council recommended implementing CRC screening, a number of European countries have initiated screening programs starting at the age of 50 years (21). In Greece, although there has been an attempt for an organized screening program according to the National Oncological Plan during 2008-2012, until now, screening has been applied only in certain hospitals on an individual basis (22). The present 
Table II. Frequency of lesions by patient according to maximum polyp size.

\begin{tabular}{|c|c|c|c|c|c|}
\hline \multicolumn{5}{|l|}{ Characteristics } & \multirow[t]{2}{*}{ P-value } \\
\hline Maximum polyp size, mm & $\leq 5$ & $6-9$ & $10-20$ & $21-40$ & \\
\hline Patients, $\mathrm{n}$ & 101 & 218 & 46 & 10 & \\
\hline Age, mean & 61 & 64 & 65.3 & 71 & 0.001 \\
\hline Male (n) & $59.4 \%(60)$ & $58.7 \%(128)$ & $63 \%(29)$ & $90 \%(9)$ & 0.25 \\
\hline \multicolumn{6}{|l|}{ Lesions (n) } \\
\hline Adenomas & $25.7 \%(26)$ & $58.3 \%(127)$ & $91.3 \%(42)$ & $100 \%(10)$ & 0.0001 \\
\hline HGD & $0 \%$ & $8.3 \%(18)$ & $19.6 \%(9)$ & $40 \%(4)$ & 0.0001 \\
\hline Cancer & $1 \%(1)$ & $0.9 \%(2)$ & $4.3 \%(2)$ & $10 \%(1)$ & 0.049 \\
\hline SSP/A & $7.9 \%(8)$ & $15 \%(33)$ & $28.3 \%(13)$ & $0 \%$ & 0.009 \\
\hline Isolated Rcolon (n) & $12.5 \%(11)$ & $23.6 \%(37)$ & $39.3 \%(11)$ & $50 \%(2)$ & 0.007 \\
\hline No polyps, mean & 1.9 & 2.5 & 3.2 & 3.2 & 0.003 \\
\hline No adenomas, mean & 1.4 & 1.7 & 1.8 & 2.6 & 0.02 \\
\hline
\end{tabular}

HGD, high grade dysplasia; SSP/A, sessile serrated polyp/adenoma; Isolated Rcolon, (right colon); No polyps, No adenomas, mean number of polyps, adenomas.

Table III. Distribution of characteristics in isolated left and right colon lesions.

\begin{tabular}{lccc}
\hline Characteristics & Right colon & Left colon & P-value \\
\hline Participants, $\mathrm{n}$ & 61 & 217 & \\
Age, years, mean & 65.3 & 62.7 & 0.05 \\
Age category \% & & & 0.35 \\
30-49 & 16.7 & 83.3 & \\
50-69 & 20 & 80 & \\
70-87 & 27.5 & 72.5 & \\
Sex \% & & & 0.08 \\
Male & 25.8 & 74.2 & \\
Female & 16.5 & 83.5 & \\
Lesions \% & & & \\
Adenomas & 29.9 & 70.1 & 0.002 \\
AA & 39 & 61 & 0.007 \\
HGD & 27.8 & 72.2 & 0.55 \\
SSP/A & 34.4 & 65.6 & 0.1 \\
No polyp, mean & 1.8 & 1.9 & 0.9 \\
AA size, mm, mean & 14.2 & 15.3 & 0.6 \\
Max polyp size \% & & & 0.009 \\
1-9 mm & 19.5 & 80.5 & \\
10-40 mm & 43.3 & 56.7 & \\
\hline AA & & & \\
\hline
\end{tabular}

AA, advanced adenoma; HGD, high grade dysplasia; SSP/A, sessile serrated polyp/adenoma.

study revealed an overall prevalence of adenomas, AA, and cancer of $28.6,9.6$ and $1.4 \%$, respectively, among asymptomatic average risk first-time participants presented by self-reference in an open access colonoscopy screening program. Similar studies of asymptomatic average-risk screening programs

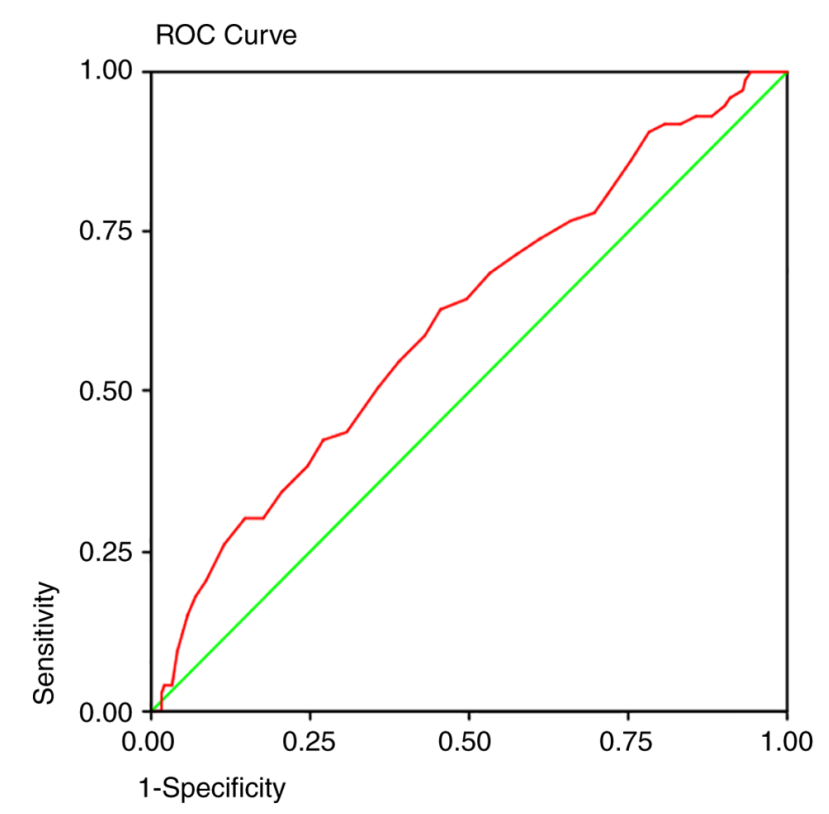

Figure 3. ROC curve for advanced adenoma detection. ROC, receiver operating characteristic.

have shown rates of adenomas, AA and cancer of 12.3-29, $2.5-7.1$ and $0.7 \%$, respectively $(13,23,24)$. The results of the present study indicated an increased prevalence rate, although the higher mean age of the participants compared with the other studies may account for the difference.

The present study demonstrated a substantial rate of adenomas in the 30-49 year old group (10.4\%) and also a high prevalence of AA (4.5\%) and cancer (1.5\%). Previous publications from the USA, the Middle, and the Far East, including asymptomatic average risk cohorts spanning from 1994-2014, have demonstrated a similar prevalence of adenomas (8.3-17.3\%) but lower AA (1-2.5\%) and cancer $(0.2 \%)$ at $40-49$ years old (25-29). Consequently, it has been 
Table IV. Frequency of lesions by patient-Comparison between early-intermediate-late age groups .

\begin{tabular}{|c|c|c|c|c|c|c|c|c|c|c|c|c|c|c|}
\hline Age (mean) & $\mathrm{n}(\%)$ & $\begin{array}{l}\text { Sex, } \\
\text { male }\end{array}$ & $\begin{array}{l}\text { Any } \\
\text { polyp }\end{array}$ & Adenoma & AA & HGD & Cancer & $\mathrm{SSP} / \mathrm{A}$ & Rcolon & $\begin{array}{c}\text { No } \\
\text { polyp } \\
\text { mean }\end{array}$ & $\begin{array}{c}\text { No } \\
\text { adenoma } \\
\text { mean }\end{array}$ & $\begin{array}{l}\text { HGD } \\
\text { size, } \\
\text { mm }\end{array}$ & $\begin{array}{l}\text { AA } \\
\text { size, } \\
\text { mm }\end{array}$ & $1-10 \mathrm{~mm}$ \\
\hline $30-49$ (43) & $67(9.4)$ & $41.8 \%$ & $34.3 \%$ & $10.4 \%$ & $4.5 \%$ & $4.5 \%$ & $1.5 \%$ & 0 & $16.7 \%$ & 2 & 1 & 10 & 9.5 & $91.3 \%$ \\
\hline $50-69(60.4)$ & $463(64.7)$ & $48.8 \%$ & $52.7 \%$ & $26.3 \%$ & $8.2 \%$ & $4.1 \%$ & $0.4 \%$ & $10.2 \%$ & $20 \%$ & 2.5 & 1.8 & 11.4 & 15.3 & $89.6 \%$ \\
\hline $70-87$ (74) & $186(26)$ & $60.8 \%$ & $58.1 \%$ & $40.9 \%$ & $15.1 \%$ & $4.8 \%$ & $3.8 \%$ & $3.8 \%$ & $27.5 \%$ & 2.4 & 1.7 & 15.3 & 15.4 & $79.6 \%$ \\
\hline P-value & & 0.006 & 0.004 & 0.0001 & 0.012 & 0.84 & 0.004 & 0.001 & 0.36 & 0.57 & 0.17 & 0.5 & 0.4 & 0.16 \\
\hline
\end{tabular}

AA, advanced adenoma; HGD, high grade dysplasia; SSP/A, sessile serrated polyp/adenoma; Rcolon, isolated right colon lesions; 1-10 mm, patients with 1-10 mm maximum polyp size.

Table V. Gender differences in different age groups.

\begin{tabular}{|c|c|c|c|c|c|c|c|c|c|}
\hline \multirow{3}{*}{$\begin{array}{l}\text { Age category } \\
\text { Participants, n }\end{array}$} & \multicolumn{3}{|c|}{ 30-49 (birth cohort 1980s) } & \multicolumn{3}{|c|}{ 50-69 (birth cohort 1960s) } & \multicolumn{3}{|c|}{ 70-87 (birth cohort 1940s) } \\
\hline & \multicolumn{3}{|c|}{67} & \multicolumn{3}{|c|}{463} & \multicolumn{3}{|c|}{186} \\
\hline & Male & Female & P-value & Male & Female & P-value & Male & Female & P-value \\
\hline $\mathrm{M} / \mathrm{F} \%(\mathrm{n})$ & $41,8(28)$ & $58.2(39)$ & & $48.8(226)$ & $51.2(237)$ & & $60.8(113)$ & $39.2(73)$ & \\
\hline Any polyp \% & 28.6 & 38.5 & 0.44 & 64.6 & 41.4 & 0.0001 & 63.7 & 49.3 & 0.06 \\
\hline No polyps, mean & 2 & 2.13 & 0.8 & 2.7 & 2.3 & 0.2 & 2.6 & 2 & 0.07 \\
\hline Polyp location & & & 0.04 & & & 0.07 & & & 0.2 \\
\hline $\mathrm{L} \%$ & 57.1 & 100 & & 74,2 & 83.5 & & 66.7 & 82.8 & \\
\hline $\mathrm{R} \%$ & 42.9 & 0 & & 25.8 & 16.5 & & 33.3 & 17.2 & \\
\hline Adenoma \% & 14.3 & 7.7 & 0.44 & 33.2 & 19.8 & 0.001 & 44.2 & 35.6 & 0.28 \\
\hline No adenoma, mean & 1 & 1 & NS & 1.8 & 1.6 & 0.3 & 1.8 & 1.5 & 0.3 \\
\hline HGD $\%$ & 7.1 & 2.6 & 0.56 & 5.3 & 3 & 0.24 & 3.5 & 6.8 & 0.3 \\
\hline HGD size, mm, mean & 9 & 12 & NS & 9.8 & 13.8 & 0.16 & 25.7 & 8.8 & 0.2 \\
\hline HGD location & & & NS & & & 0.6 & & & NS \\
\hline $\mathrm{L} \%$ & & 100 & & 50 & 62.5 & & 66.7 & 60 & \\
\hline $\mathrm{R} \%$ & 100 & & & 50 & 37.5 & & 33.3 & 40 & \\
\hline AA $\%$ & 7.1 & 2.6 & NS & 10.6 & 5.9 & 0.08 & 17.7 & 11 & 0.3 \\
\hline AA size, mm, mean & 9 & 10 & NS & 15 & 16 & 0.6 & 16.3 & 13.2 & 0.45 \\
\hline AA location & & & 0.33 & & & 0.09 & & & 0.2 \\
\hline $\mathrm{L} \%$ & & 100 & & 48.1 & 78.6 & & 42.1 & 75 & \\
\hline $\mathrm{R} \%$ & 100 & & & 51.9 & 21.4 & & 57.9 & 25 & \\
\hline Cancer \% & 0 & 2.6 & NS & 0 & 0.8 & 0.49 & 4.4 & 2.7 & 0.7 \\
\hline Serrated polyp/adenoma $\%$ & 0 & 0 & & 11.5 & 8.9 & 0.36 & 5.3 & 1.4 & 0.25 \\
\hline Maximum polyp size, $\mathrm{mm}$ & & & 0.27 & & & 0.5 & & & 0.14 \\
\hline$\leq 5$ & $62.5 \%$ & $26.7 \%$ & & $28.1 \%$ & $31.6 \%$ & & $19.4 \%$ & $16.7 \%$ & \\
\hline $6-10$ & $37.5 \%$ & $60 \%$ & & $58.9 \%$ & $55.1 \%$ & & $54,2 \%$ & $75 \%$ & \\
\hline $11-20$ & 0 & $13.3 \%$ & & $11 \%$ & $13.3 \%$ & & $18.1 \%$ & $5.6 \%$ & \\
\hline $21-40$ & 0 & 0 & & $2.1 \%$ & 0 & & $8.3 \%$ & $2.8 \%$ & \\
\hline NNS-adenoma & 18 & 22 & & 6 & 10 & & 4 & 7 & \\
\hline
\end{tabular}

HGD, high grade dysplasia; AA, advanced adenoma; No polyps, No adenomas, mean number of polyps or adenoma per patient; L, left; R, right.

proposed that this age group with risk factors such as obesity should start screening at 45 years old (25).
Subcentimetric polyps constituted $85 \%$ of the cohort, which is consistent with other studies previously mentioned $(13,14)$. 
Table VI. Area Under The Curve and Cut-off points of screening colonoscopy for identifying disease positive patients.

\begin{tabular}{|c|c|c|c|c|c|c|}
\hline & Area & $\begin{array}{l}\text { Asymptomatic } \\
\text { significance }\end{array}$ & $95 \%$ CI & Cut-off value & Sensitivity & Specificity \\
\hline Polyps & 0.564 & 0.003 & $0.522-0.606$ & 50 years & 0.92 & 0.85 \\
\hline Adenomas & 0.631 & 0.000 & $0.586-0.675$ & 50 years & 0.95 & 0.86 \\
\hline $\mathrm{AA}$ & 0.613 & 0.002 & $0.545-0.682$ & 50 years & 0.93 & 0.88 \\
\hline Proximal lesions & 0.573 & 0.005 & $0.523-0.622$ & 50 years & 0.93 & 0.87 \\
\hline Adenomas-male & 0.607 & 0.001 & $0.548-0.666$ & 50 years & 0.95 & 0.87 \\
\hline Adenomas-female & 0.641 & 0.036 & $0.569-0.712$ & 50 years & 0.93 & 0.85 \\
\hline Adenomas & & & & 48 years & 0.98 & 0.90 \\
\hline Adenomas-male & & & & 48 years & 0.98 & 0.92 \\
\hline Adenomas-female & & & & 46 years & 0.98 & 0.91 \\
\hline
\end{tabular}

CI, confidence interval.

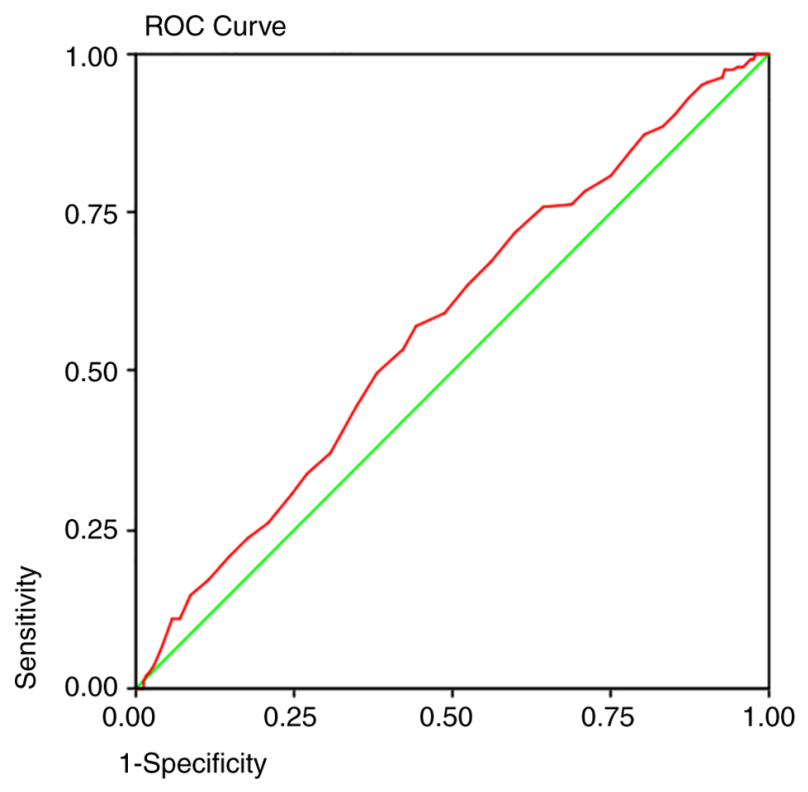

Figure 4. ROC curve for proximal lesions detection. ROC, receiver operating characteristic.

The present study noted that $8.3 \%$ of the $6-9 \mathrm{~mm}$ polyps could host advanced lesions, such as hgd, or coexist with cancer in $0.9 \%$ of the cases. In the literature so far, the pooled rate of AA in small polyps $(6-9 \mathrm{~mm})$ is $~ 4.9 \%$ (30) in asymptomatic average-risk groups. Other studies from Europe and America, including asymptomatic but not exclusively average-risk individuals, report the presence of AA in 1.6-12.8\% of the small polyps $(15,31,32)$. This is to remind the endoscopists that participate in screening programs not to dismiss subcentimetric polyps easily and to be cautious about the radical excision of such lesions.

These data regarding young adults and small polyps necessitate reconsideration of current recommendations. The natural history of precancerous lesions suggests that $37 \%$ of the adenomas and $91 \%$ of AA will eventually progress to cancer with an annual rate of $2.5-5.5 \%$ for AA, while $\sim 6 \%$ of subcentimetric adenomas will become AA in 2-3 years (33-35). This

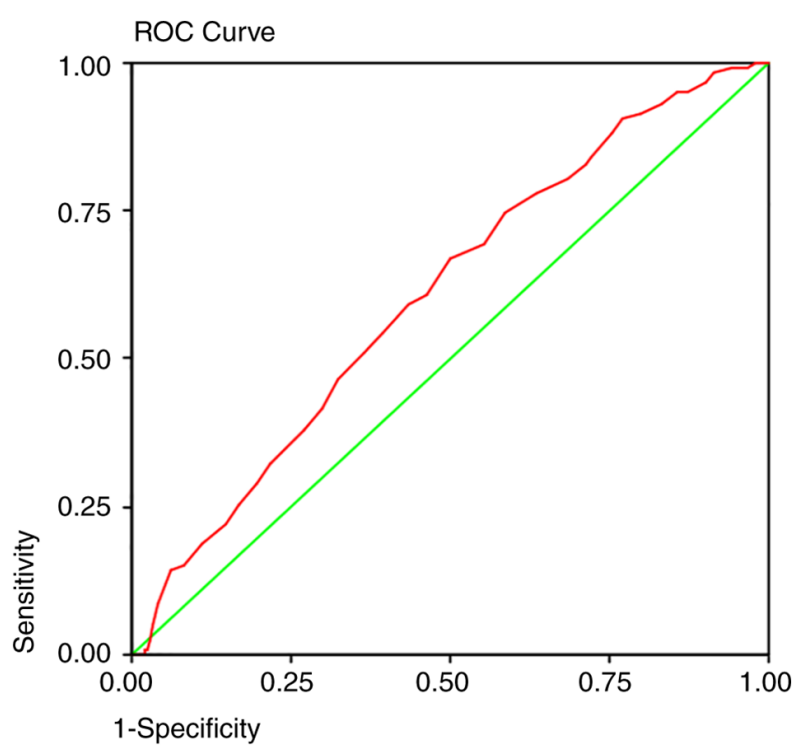

Figure 5. ROC curve for adenoma detection in males. ROC, receiver operating characteristic.

indicates that advanced lesions at the early age group will become cancer almost by certainty after $20-30$ years, meaning in the 6 th or 7 th decade of life.

There are several but consistent data gathered from different continents (America, Australia and Europe) $(6,9,11)$ noting that although absolute $\mathrm{CRC}$ incidence rates are lower in women compared with men $(8,11)$, the annual percentage changes for women 30-49 years old are higher between 1994 and 2016 ranging between APC 4.73-6.8\% $(6,10)$ and they appeared to have been tripled (APC: 12) since 2009 (5). In Europe, this percentage change was associated with a cohort effect, with the turning point being in the early 1990s $(5,6)$. Another study, including first-time asymptomatic average-risk individuals, showed that women $<50$ years old had more advanced neoplasia compared with men (6.2 vs. $0.6 \%$ respectively) (23). The present study noted an increase in prevalence rates of polyps and a larger maximum polyp size in women 30-49 years old relative to men. The majority of the serious 


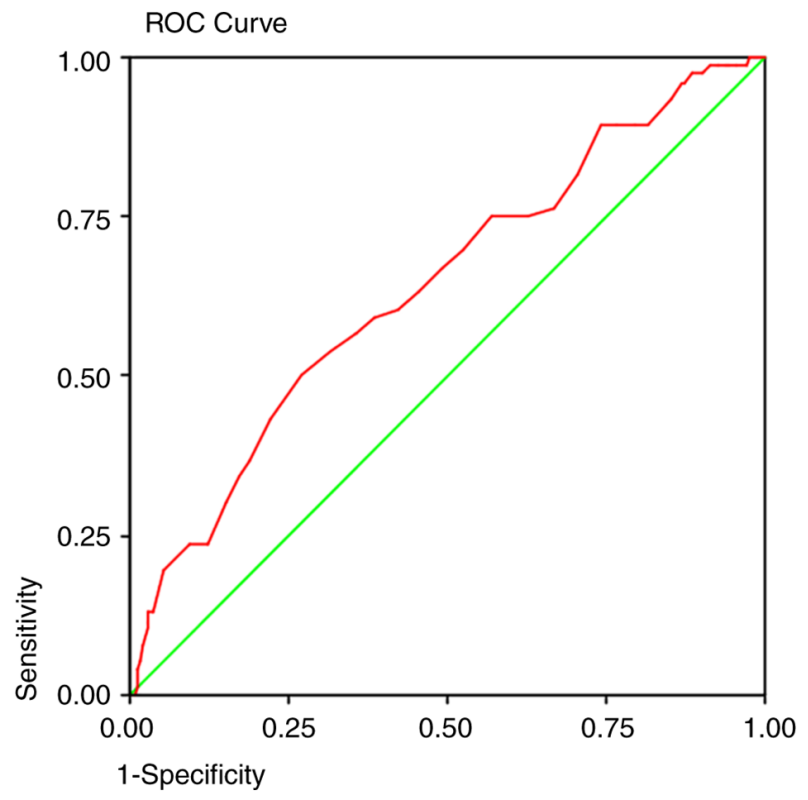

Figure 6. ROC curve for adenoma detection in females. ROC, receiver operating characteristic.

lesions were located in the left colon the opposite to that in men. If this tendency is validated in other studies, it would be reasonable to lower the screening age for younger women $<50$ years old with a flexible sigmoidoscopy as the initial examination followed by colonoscopy at a later age according to current guidelines.

The above findings differed in older age groups, where men $>50$ years had statistically more serious lesions compared with women while maintaining an increased prevalence of right colon lesions. These findings were consistent with other studies presenting increased incidence of proximal malignant neoplasia in men 20-39 years old, especially since $2010(5,12)$, with higher left-sided lesions in women (10).

Furthermore, in the present study, proximal lesions were found in a substantial proportion of participants (21.9\%) and $39 \%$ of AA were located solely in the right colon. Right colon lesions were detected in older age compared with distal lesions with a predilection in men and larger maximum polyp size. This notification is crucial for developing a screening program and the determination of screening methods as sigmoidoscopy and fecal tests are inadequate or less sensitive, respectively, for the detection of proximal lesions (36). The location has significant implications for screening since there is a higher missing rate for proximal lesions (37) and these lesions are out of the reach of sigmoidoscopy. In one meta-analysis, once only sigmoidoscopy at the age of 55 years decreased the incidence and mortality of CRC by 18 and $28 \%$, respectively (38). This could be an option for younger age women in whom the majority of lesions lie in the left colon and since the NNS for the finding of one adenoma is higher compared with men (22 vs. 18), it is difficult to justify a screening colonoscopy at ages $<50$ years.

The ROC curves revealed that with the current recommendation of screening colonoscopy at 50 years, $5-7 \%$ of adenomas will remain undetected either due to the inability of the detection method itself or because of a late referral of individuals. Since the first proposal for initiation of screening at 45 years for African Americans was suggested in 2005 (39), certain Medical Societies, such as in Saudi Arabia in 2015 (19), the US Multi-society Task Force in 2017 (20) and recently the American Cancer Society (18) have adopted this recommendation for all adult average-risk population. In the present case, we would expect to detect $98 \%$ of the overall adenomas in both genders if we decided to lower the screening age at 48 years in men and 46 years in women. This age group is also compatible with epidemiological data showing that CRC is an important health risk, being the fourth most common cancer with $74.3 \%$ of its cases clustering in between 40 and 49 years old (40). Cost-effectiveness analysis modeling using estimated adenoma prevalence in different age cohorts similar to the present study has concluded positively for starting screening at 45 years (41). The selection of the acceptable age for initiation of screening is a matter of public health policy and available resources. Since the purpose of screening is to detect precancerous lesions, meaning in practice adenomas, it would be reasonable to detect as many of them as possible and as early in life as possible since the cancers that are diagnosed at the age of 60 years stem from adenomas at the age of 40 years. Following this concept, if it is a public necessity to detect $98 \%$ of the adenomas in the screened population, one would need to start screening at the age of 48 years and if one would like to detect the same number in women as in men, then the initiation of screening should be at 46 years for women.

The present study has certain limitations. Some limitations are inherent to the study type and the sample size. Although the participants were prospectively entered into the database, this is an observational cross-sectional study with an adequate overall sample size but with a restricted earlier age cohort and consisted of self-referred individuals since there is no organized national screening program in Greece. This might introduce type II errors and selection bias because the included individuals could be considered more health-oriented with health-seeking behaviors. A future meta-analysis could properly collect and incorporate more data from various studies regarding young adults who unfortunately remain behind screening intentions.

Additionally, in one-third of the procedures, trainees were actively involved, theoretically increasing the risk of missing lesions. The present study was aware that proposals regarding screening procedures at a population level should consider multidimensional prerequisites concerning the disease itself, health resources and local cost-effectiveness analysis. This epidemiological analysis aims to provide answers about the active disease profile of the Greek population, which is of fundamental importance in activating the cascade of further endeavor.

In conclusion, this is the largest study of colorectal cancer screening of a Greek average risk population sample so far. It noted emerging trends of increased prevalence in precancerous and malignant colon lesions, especially important for younger adults and, more specifically, women. It also focused on the small polyps that host significant lesions in the screening cohort and also focused on the proximal location of lesions in the right colon as an additional parameter of missing lesions and access strategy. Based on this disturbing data and the corroborative epidemiologic surveillance profile from other countries, it was proposed to lower the initiation age of screening at 48 years for men with colonoscopy and 
at 46 years for women with once-only sigmoidoscopy with subsequent surveillance following current guidelines from the age of 50 years by colonoscopy. These proposals are based on a Greek population sample and cannot be extrapolated to other countries.

\section{Acknowledgements}

Not applicable.

\section{Funding}

No funding was received.

\section{Availability of data and materials}

The datasets used and/or analyzed during the current study are available from the corresponding author on reasonable request.

\section{Authors' contributions}

VP was responsible for conception and design of the present study. Analysis and interpretation of the data was performed by VP, GF, PK, NV, SV, GL, ID and EK. VP and EK drafted the article and VP, ID and EK critically revised the article for important intellectual content. VP, NV and SV confirm the authenticity of all raw data. All authors reviewed and approved the final manuscript.

\section{Ethics approval and consent to participate}

All participants provided written informed consent. The study has been performed in accordance with the ethical standards of the 1964 Declaration of Helsinki and its later amendments. The Institutional Review board of the Sismanogleio General Hospital approved the study protocol (approval number 399/18-4-2019).

\section{Patient consent for publication}

Not applicable.

\section{Competing interest}

The authors declare that they have no competing interests.

\section{Authors' information}

Vasileios Panteris: ORCID 0000-0003-1165-8927.

\section{References}

1. Edwards BK, Noone AM, Mariotto AB, Simard EP, Boscoe FP, Henley SJ, Jemal A, Cho H, Anderson RN, Kohler BA, et al: Annual Report to the Nation on the status of cancer, 1975-2010, featuring prevalence of comorbidity and impact on survival among persons with lung, colorectal, breast, or prostate cancer. Cancer 120: 1290-1314, 2014.

2. Jemal A, Ward EM, Johnson CJ, Cronin KA, Ma J, Ryerson B, Mariotto A, Lake AJ, Wilson R, Sherman RL, et al: Annual report to the Nation on the status of cancer, 1975-2014, featuring survival. J Natl Cancer Inst 109: djx030, 2017.
3. Henley SJ, Ward EM, Scott S, Ma J, Anderson RN, Firth AU, Thomas CC, Islami F, Weir HK, Lewis DR, et al: Annual report to the nation on the status of cancer, part I: National cancer statistics. Cancer 126: 2225-2249, 2020

4. Siegel RL, Fedewa SA, Anderson WF, Miller KD, Ma J, Rosenberg PS and Jemal A: Colorectal cancer incidence patterns in the United States, 1974-2013. J Natl Cancer Inst 109: djw322, 2017.

5. Exarchakou A, Donaldson LJ, Girardi F and Coleman MP: Colorectal cancer incidence among young adults in England: Trends by anatomical sub-site and deprivation. PLoS One 14: e0225547, 2019.

6. Vuik FE, Nieuwenburg SA, Bardou M, Lansdorp-Vogelaar I, Dinis-Ribeiro M, Bento MJ, Zadnik V, Pellisé M, Esteban L, Kaminski MF, et al: Increasing incidence of colorectal cancer in young adults in Europe over the last 25 years. Gut 68: 1820-1826, 2019.

7. Bhandari A, Woodhouse M and Gupta S: Colorectal cancer is a leading cause of cancer incidence and mortality among adults younger than 50 years in the USA: A SEER-based analysis with comparison to other young-onset cancers. J Investig Med 65: 311-315, 2017.

8. Ohri A, Robinson A, Liu B, Bhuket T and Wong R: Updated assessment of colorectal cancer incidence in the U.S. by age, sex, and race/ethnicity. Dig Dis Sci 65: 1838-1849, 2020.

9. Troeung L, Sodhi-Berry N, Martini A, Malacova E, Ee H, O'Leary P, Lansdorp-Vogelaar I and Preen DB: Increasing incidence of colorectal cancer in adolescents and young adults aged 15-39 years in Western Australia 1982-2007: Examination of Colonoscopy History. Front Public Health 5: 179, 2017.

10. Frostberg $\mathrm{E}$ and Rahr HB: Clinical characteristics and a rising incidence of early-onset colorectal cancer in a nationwide cohort of 521 patients aged 18-40 years. Cancer Epidemiol 66: 101704, 2020.

11. Singh KE, Taylor TH, Pan CG, Stamos MJ and Zell JA: Colorectal cancer incidence among young adults in California. J Adolesc Young Adult Oncol 3: 176-184, 2014.

12. Crosbie AB, Roche LM, Johnson LM, Pawlish KS, Paddock LE and Stroup AM: Trends in colorectal cancer incidence among younger adults-Disparities by age, sex, race, ethnicity, and subsite. Cancer Med 7: 4077-4086, 2018.

13. Bokemeyer B, Bock H, Hüppe D, Düffelmeyer M, Rambow A, Tacke W and Koop H: Screening colonoscopy for colorectal cancer prevention: Results from a German online registry on 269000 cases. Eur J Gastroenterol Hepatol 21: 650-655, 2009.

14. Lowenfels AB, Williams JL, Holub JL, Maisonneuve P and Lieberman DA: Determinants of polyp size in patients undergoing screening colonoscopy. BMC Gastroenterol 11: 101, 2011.

15. Kolligs FT, Crispin A, Graser A, Munte A, Mansmann U and Göke B: Risk factors for advanced neoplasia within subcentimetric polyps: Implications for diagnostic imaging. Gut 62: 863-870, 2013.

16. Panteris V, Vezakis A and Triantafillidis JK: Should hot biopsy forceps be abandoned for polypectomy of diminutive colorectal polyps? World J Gastroenterol 24: 1579-1582, 2018.

17. Panteris V: The problem with cold snare polypectomy of diminutive colorectal polyps. Scand J Gastroenterol 55: 1389, 2020.

18. Wolf AMD, Fontham ETH, Church TR, Flowers CR, Guerra CE, LaMonte SJ, Etzioni R, McKenna MT, Oeffinger KC, Shih YT, et al: Colorectal cancer screening for average-risk adults: 2018 guideline update from the American Cancer Society. CA Cancer J Clin 68: 250-281, 2018.

19. Bénard F, Barkun AN, Martel M and von Renteln D: Systematic review of colorectal cancer screening guidelines for average-risk adults: Summarizing the current global recommendations. World J Gastroenterol 24: 124-138, 2018.

20. Rex DK, Boland CR, Dominitz JA, Giardiello FM, Johnson DA, Kaltenbach T, Levin TR, Lieberman D and Robertson DJ: Colorectal cancer screening: Recommendations for physicians and patients from the U.S. Multi-society task force on colorectal cancer. Gastroenterology 153: 307-323, 2017.

21. Navarro M, Nicolas A, Ferrandez A and Lanas A: Colorectal cancer population screening programs worldwide in 2016: An update. World J Gastroenterol 23: 3632-3642, 2017.

22. Altobelli E, Lattanzi A, Paduano R, Varassi G and di Orio F: Colorectal cancer prevention in Europe: Burden of disease and status of screening programs. Prev Med 62: 132-141, 2014.

23. Boursi B, Halak A, Umansky M, Galzan L, Guzner-Gur H and Arber N: Colonoscopic screening of an average-risk population for colorectal neoplasia. Endoscopy 41: 516-521, 2009. 
24. Yang MH, Rampal S, Sung J, Choi YH, Son HJ,Lee JH, Kim YH, Chang DK, Rhee PL, Rhee JC, et al: The prevalence of colorectal adenomas in asymptomatic Korean men and women. Cancer Epidemiol Biomarkers Prev 23: 499-507, 2014.

25. Hong SN, Kim JH, Choe WH, Han HS, Sung IK, Park HS and Shim CS: Prevalence and risk of colorectal neoplasms in asymptomatic, average-risk screenees 40 to 49 years of age. Gastrointest Endosc 72: 480-489, 2010.

26. Hemmasi G, Sohrabi M, Zamani F, Ajdarkosh H, Rakhshani N Khoonsari M, Ameli M and Hatami K: Prevalence of colorectal adenoma in an average-risk population aged 40-50 versus 50-60 years. Eur J Cancer Prev 24: 386-390, 2015.

27. Rundle AG, Lebwohl B, Vogel R, Levine S and Neugut AI: Colonoscopic screening in average-risk individuals ages 40 to 49 vs 50 to 59 years. Gastroenterology 134: 1311-1315, 2008.

28. Strul H, Kariv R, Leshno M, Halak A, Jakubowicz M, Santo M, Umansky M, Shirin H, Degani Y, Revivo M, et al: The prevalence rate and anatomic location of colorectal adenoma and cancer detected by colonoscopy in average-risk individuals aged 40-80 years. Am J Gastroenterol 101: 255-262, 2006.

29. Leshno A, Moshkowitz M, David M, Galazan L, Neugut AI, Arber N and Santo E: Prevalence of colorectal neoplasms in young, average risk individuals: A turning tide between East and West. World J Gastroenterol 22: 7365-7372, 2016.

30. Hassan C, Pickhardt PJ, Kim DH, Di Giulio E, Zullo A, Laghi A, Repici A, Iafrate F, Osborn J and Annibale B: Systematic review: Distribution of advanced neoplasia according to polyp size at screening colonoscopy. Aliment Pharmacol Ther 31: 210-217, 2010.

31. Butterly LF, Chase MP, Pohl H and Fiarman GS: Prevalence of clinically important histology in small adenomas. Clin Gastroenterol Hepatol 4: 343-348, 2006.

32. Gupta N, Bansal A, Rao D, Early DS, Jonnalagadda S, Wani SB, Edmundowicz SA, Sharma P and Rastogi A: Prevalence of advanced histological features in diminutive and small colon polyps. Gastrointest Endosc 75: 1022-1030, 2012.

33. Brenner H, Hoffmeister M, Stegmaier C, Brenner G, Altenhofen L and Haug U: Risk of progression of advanced adenomas to colorectal cancer by age and sex: Estimates based on 840,149 screening colonoscopies. Gut 56: 1585-1589, 2007.
34. Vleugels JLA, Hazewinkel Y, Fockens P and Dekker E: Natural history of diminutive and small colorectal polyps: A systematic literature review. Gastrointest Endosc 85: 1169-1176.e1, 2017.

35. Pickhardt PJ, Kim DH, Pooler BD, Hinshaw JL, Barlow D, Jensen D, Reichelderfer M and Cash BD: Assessment of volumetric growth rates of small colorectal polyps with CT colonography: A longitudinal study of natural history. Lancet Oncol 14: 711-720, 2013.

36. Meza R, Jeon J, Renehan AG and Luebeck EG: Colorectal cancer incidence trends in the United States and United kingdom: Evidence of right- to left-sided biological gradients with implications for screening. Cancer Res 70: 5419-5429, 2010.

37. Haug U, Knudsen AB, Brenner H and Kuntz KM: Is fecal occult blood testing more sensitive for left-versus right-sided colorectal neoplasia? A systematic literature review. Expert Rev Mol Diagn 11: 605-616, 2011.

38. Massat NJ, Moss SM, Halloran SP and Duffy SW: Screening and primary prevention of colorectal cancer: A review of sex-specific and site-specific differences. J Med Screen 20: 125-148, 2013

39. Agrawal S, Bhupinderjit A, Bhutani MS, Boardman L, Nguyen C, Romero Y, Srinivasan R and Figueroa-Moseley C; Committee of Minority Affairs and Cultural Diversity, American College of Gastroenterology: Colorectal cancer in African Americans. Am J Gastroenterol 100: 515-523, discussion 514, 2005.

40. Fairley TL, Cardinez CJ, Martin J, Alley L, Friedman C, Edwards B and Jamison P: Colorectal cancer in U.S. adults younger than 50 years of age, 1998-2001. Cancer 107 (Suppl 5): S1153-S1161, 2006.

41. Knudsen AB, Zauber AG, Rutter CM, Naber SK, Doria-Rose VP, Pabiniak C, Johanson C, Fischer SE, Lansdorp-Vogelaar I and Kuntz KM: Estimation of benefits, burden, and harms of colorectal cancer screening strategies: Modeling study for the US preventive services task force. JAMA 315: 2595-2609, 2016.

This work is licensed under a Creative Commons Attribution-NonCommercial-NoDerivatives 4.0 International (CC BY-NC-ND 4.0) License. 